\title{
Criteria and Procedures of Analysis Applicable in the Evaluation of the Archaeological Heritage
}

\author{
Ana Maria Grămescu, Ana Maria Daniela Barbu and Alexandru Ioniță
}

\begin{abstract}
The implementation of the European policy in the field of built heritage involved, for each country, the creation of the legal, administrative and financial means necessary for the implementation of the rehabilitation policy.The research procedures and the intervention measures must be correlated with the degree of damage (degradation) of the materials, as an effect of earthquakes that the construction has endured, of others specific exploitation actions, differential land settlements, uncontrolled human interventions or environmental factors. Archaeologists around the world have developed a procedure for evaluating archaeological resources, so it appeared in the early 1970s, an example being that developed by Schaffer and Gumerman in 1977. Archaeological sites have the ability to demonstrate how the society functioned at a given time, the level of civilization, the progress of science and technology, what processes have taken place, how the activity unfolded and the extent of a technological practice or other occupation history. They can demonstrate the main characteristics of a place or process that may be rare or common. In the article, the authors develop the principles that lie at the base of quantifying the values of archaeological heritage, presenting some case studies.
\end{abstract}

\section{Keywords - archaeological heritage, evaluation of archaeological sites,} underground constructions

\section{INTRODUCTION}

Romania's accession to the European Union emphasized the position of society in relation to the existing built heritage, as well as the need to preserve and preserve cultural values. There are a variety of projects and programs for the rehabilitation of heritage, and the preservation of historical substance.

At European level, there is no legislation in the technical field meant to standardize and harmonize the principles and methods of the intervention works as well as the quantification of cultural values. These are left at the discretion of the specialists, who make their contribution both in establishing the value of the monument and in establishing the appropriate intervention measures for each individual case. The implementation of the European policy in the field of built heritage involved, for each country, the creation of the legal, administrative and financial means necessary for the implementation of the rehabilitation policy. In this context, in Romania, Law 422/2001, on the protection of historical heritage, welcomes the application of European policies at national level Choosing a correct analysis and intervention strategy is conditioned by the complete 


\section{sciendo}

114 Ovidius University Annals Series: Civil Engineering, Year 23, 2021

understanding of the individual deficiencies of the structural and non-structural elements, their combined effect on the mechanism of the seismic behavior of the building, as well as the overall deficiencies regarding the resistance, deformability, redundancy, regularity structural.

The research procedures and the intervention measures must be correlated with the degree of damage (degradation) of the materials, as an effect of earthquakes that the construction has endured, of others specific exploitation actions, differential land settlements, uncontrolled human interventions or environmental factors. The international charter for the management of the archaeological heritage (ICOMOS 1990), notes that the archaeological heritage is "the part of the material inheritance that includes primary archaeological methods, namely the vestiges of human existence, underwater sites together with the associated cultural material". Buildings are not considered archaeological sites, unless they are buried, respectively with no prospect of economic use.

Archaeologists around the world have developed a procedure for evaluating archaeological resources, so it appeared in the early 1970s, an example being that developed by Schaffer and Gumerman in 1977.

This procedure is based on criteria such as:

- The scientific significance of archaeological materials;

- The potential to provide evidence about the past or the ability to represent a category of archaeological phenomena;

- Representativeness to the extent that it allows the exchange of some knowledge about the past.

In this regard, New Zealand presents a set of procedures for the assessment of archaeological values.

As is known, the purpose of archaeological assessments is:

- The case of destruction;

- Issuing a resource agreement according to the legal provisions regarding the management of resources for the registration of historical sites;

- Representativeness.

For the evaluation procedure, an intensive investigation program is initiated to allow a decision to be made:

- destruction;

- attenuation;

- Protection.

The investigations are based on invasive techniques.

Motivated by the multiple risks that can be particular in the evaluation it is recommended that the evaluation be done by professionals. The fundamental risk in an evaluation is the incorrect diagnosis. Many however, real estate developers do not use professionals. There is also the risk that the identified fragments will not be evaluated correctly, in which case the archaeological site is damaged, which may be wrongly evaluated in the analysis of the fundamental value criteria.

According to ICOMOS recommendations, the evaluation criteria for archaeological sites are:

- Aesthetic criteria;

- Historical criteria;

- Scientific criteria;

- Social criteria;

- Ethnic significance. 
The significance can be evaluated by place historian, by placing the resources discovered in a historical framework, by comparative information.

The specialized literature identified 8 representative elements in the evaluation of significance [1], of which we mention:

- Period of edification;

- Rarity;

- The value of the assembly;

- Storage conditions;

- Technical status;

- Fragility of the elements;

- Vulnerability;

- Diversity and potential.

Other valuable components may be:

- The value of the arrangements (with reference to the knowledge / educational or tourist resource)

- Conservation value (the potential of archaeological values to improve the value of the site by integrating the archaeological values with those of conservation).

It can be observed that the meanings in the gradual etymology assigned to archaeological sites can be:

- Exceptional significance;

- Significant significance;

- The archaeological site has some meanings, or

- The archaeological site has little significance.

In the national legislation through the OG 43/2000 updated, it is noted that the archaeological heritage represents an ensemble of archaeological assets consisting of: the archaeological sites inscribed in the national archaeological repertoire, except those destroyed or disappeared, and the sites classified in the list of historical monuments, located above, underground or underwater, comprising archaeological remains: settlements, necropolis, structures, constructions, groups of buildings, as well as land with archaeological potential identified, defined according to the law.

Archaeological research covers all the measures of a scientific and technical nature, meant to ensure the prospecting, identification, discovery by archaeological excavations, investigation, and harvesting, recording and scientific valorization, including publication, of the archaeological heritage. Archaeological research can be carried out systematically which is a long-term research and is based on a project prepared for this purpose and preventive research, which is part of the strategies of sustainable development, economicsocial, tourism, urban planning and spatial planning, at national and local level. The latter refers to: the researchers determined by the works of construction, modification, extension or repair regarding communication paths, technical-public facilities, including underground and underwater, excavations, quarrying, construction of master networks, arrangements for land improvements, telecommunication networks, location of telecommunication relays and antennas, land research and prospecting - drilling and excavation - necessary for geotechnical studies, location of ballast and gas and oil wells, as well as any other works that affect the surface of the soil and subsoil, in the areas with archaeological heritage found, whether it is executed in the urban or extra-urban areas and regardless of the form of land ownership. At the same time, they can be initiated in known and researched archaeological heritage, as well as determined by the works of partial or total restoration of historical monuments, carried out according to the legislation in force regarding the protection of historical monuments. 


\section{sciendo}

116 Ovidius University Annals Series: Civil Engineering, Year 23, 2021

An area with archaeological potential highlighted by accident is formed by the land in which the existence of the archaeological heritage assets were highlighted, as a result of:

1. human actions, other than certified archaeological research, such as: construction work, geological survey work, including remote sensing, agricultural work, as well as other types of works and research conducted underground or underwater;

2. the actions of natural factors, such as: earthquakes, landslides, floods, soil erosion and others, and for which an archaeological research is needed in order to record and use their scientific value.

\section{CharaCterization OF THE RESEARCH IN DOBROGEA}

An example of preventive research is the research carried out through the development of the modern city of Constanta. We exemplify in this regard the attenuation of two basilicas by the construction of blocks around 1978, or another example is the discoveries made in 1959 when, on the occasion of the works of a block near the Museum of National History and Archeology Constanta, a wall was discovered and some fragments of ancient mosaic. The whole area was constituted in an archaeological reserve and for almost 10 years research works were carried out, today being included in the list of historical monuments at the position CT-I-m-A-02553.05 [13]. In parallel, the building that houses the mosaic, located above the warehouses of the ancient port, was built.

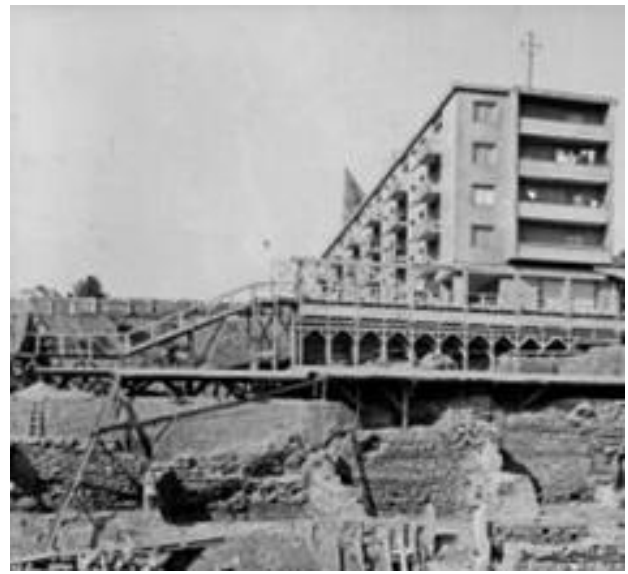

Fig. 1 Images during the works [2]

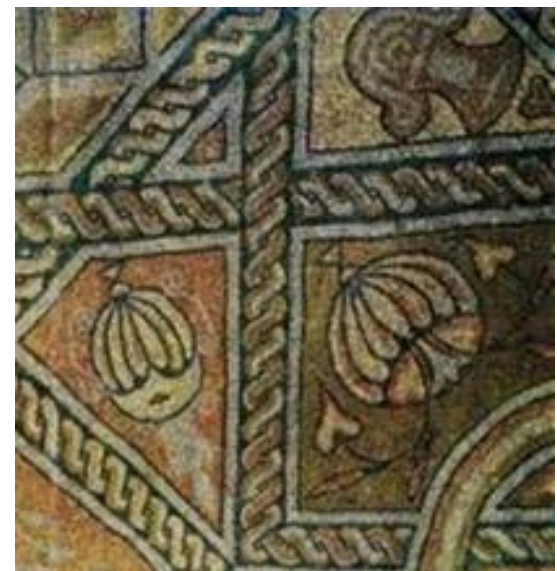

Fig. 2 Mosaic piece

The Roman baths of the old ancient city - Tomis - classified in the list of historical monuments Code LMI - CT-I-m-A-02553.12, are located at approx. $150 \mathrm{~m}$ southeast of the Roman Building with Mosaic[13]. The baths were built at the same time as the Roman Building (III-VI centuries). Currently there are about 300 square meters of the former public baths, baths that were covered with white marble tiles, under which channels and tubes passed, a heating system peculiar to antiquity, called hypocaustum.

The galleries built by the Romans, currently in the list of historical monuments at the position CT-I-m-A-02553.10, had the role of water supply, but could also have a defensive character. The system of aqueducts and galleries under Tomis was built in the second half of the 2nd century $\mathrm{AD}$, when the fortress fulfilled the metropolitan function of the left Euxin Bridge. 


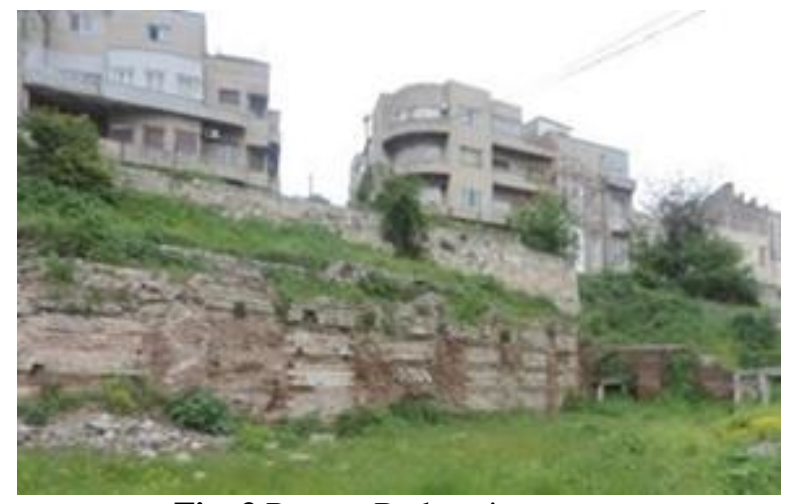

Fig. 3 Roman Baths - in present

The Tomis had as a source of water the Canara area (now the city of Ovidiu) on the southwestern shore of Lake Siutghiol, at that time, the Black Sea bay. There is a whole network of underground galleries connected to each other, with built-in ventilation channels and numerous exit holes. The aqueducts were preserved in their entirety. The upper part has the vaulted form made of limestone blocks connected and equalized with a particularly hard mortar. The baths had impressive pools and reservoirs.
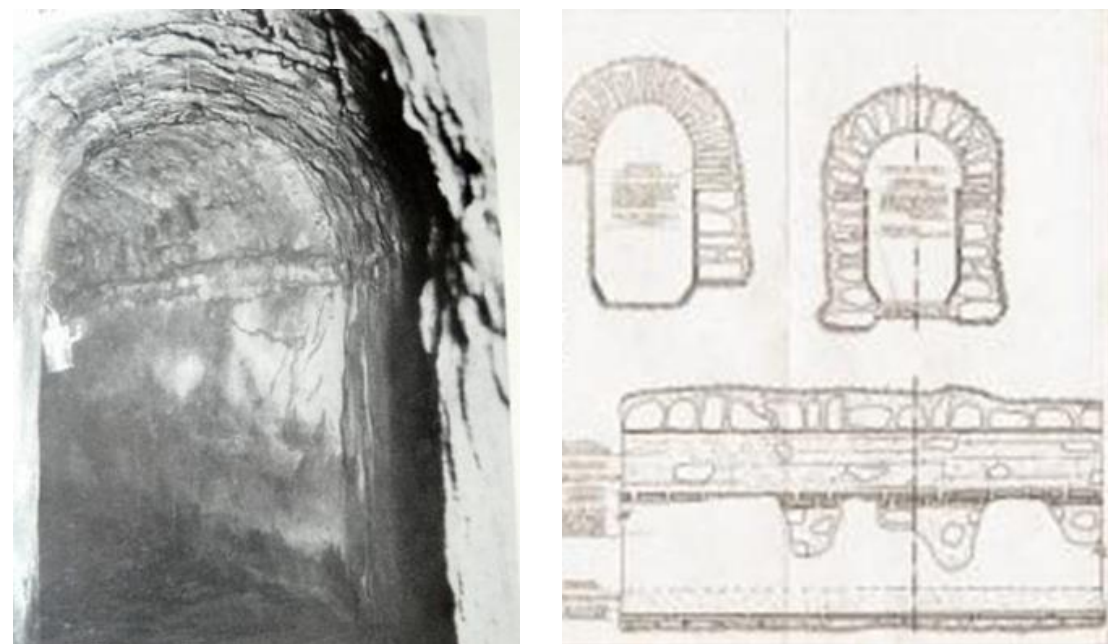

Fig. 4 Underground galleries

Almost all the surface of the Peninsula was found traces of urban dwelling (area recorded in the list of historical monuments on the CT-ImA-02553.07. The development of the modern city has only preserved a few of them, especially on the land near the Cathedral of St. Peter and Paul., also framed by the streets of the Archdiocese and Elisabeta Boulevard [2].

With regard to the living areas, it is noted that for the Greek period are found in the area with the limits of the streets Dimitrie Cantemir and Petru Rareş, and for the Roman and Roman-Byzantine period are found until Ferdinand Boulevard.

The Cathedral Park shows eloquently the level of urbanism of the ancient Tomis, observing the housing system and the rectangular street plot (including the sewerage system). 


\section{sciendo}

The streets are paved with molded stone, with drainage channels in the middle. The houses are presented in the form of rectangular arranged structures. The buildings on Str. The archbishops, although lined with the street, have deep oblique walls, which confirms that they were used by the foundations of the ancient houses arranged in the same directions.

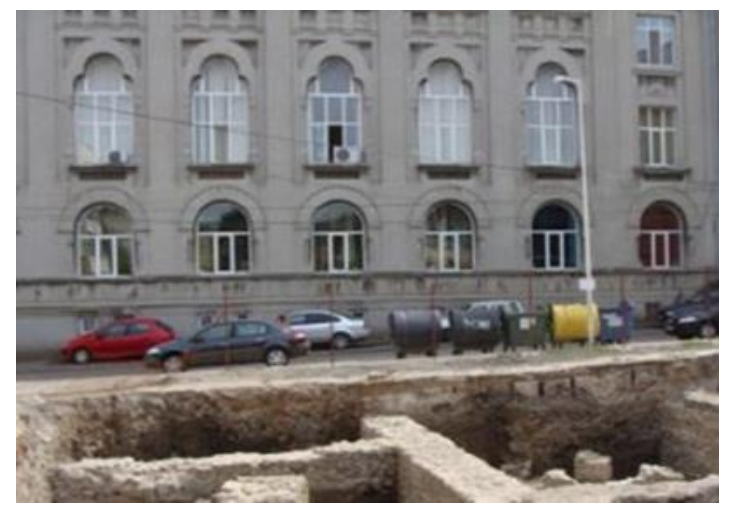

Fig. 5 Images during excavations for the construction of underground garages located adjacent to the cathedral

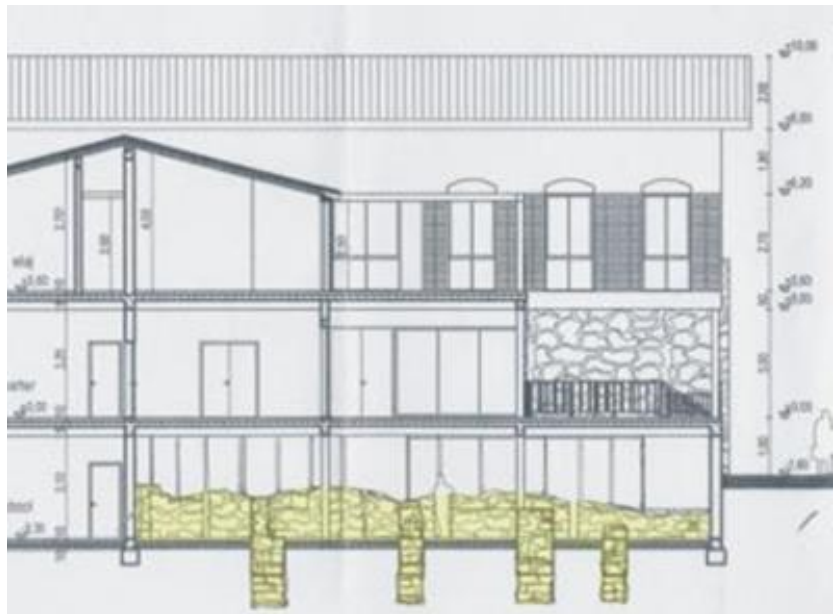

Fig. 6 Housing construction over the old structures - Ovidiu Square

With regard to the analysis of the evaluation criteria, it can be observed that these vestiges have been classified by the specialists in the list of historical monuments of national importance, an aspect that attributes historical, scientific, social, aesthetic elements to them.

For the evaluation of the significance it can be observed that the period of building, the rarity at national level, the diversity and the potential confer an exceptional significance to them. These potential qualities are supported by the restoration and enhancement policy of the ancient vestiges - their introduction in the tourist circuit.

It is worth noting that both in the country, but also at European level, these monuments of the specificity of the Roman baths are restored and introduced in the tourist circuit. Their restoration is possible with the restoration of the destroyed areas with materials recovered from other sections that could not be reconstructed with the use of the same technologies and partially with the use of concrete in the upper curved elements of the galleries. 


\section{sciendo}

An example of this is the rehabilitation of the Roman baths in Trier (Germany):

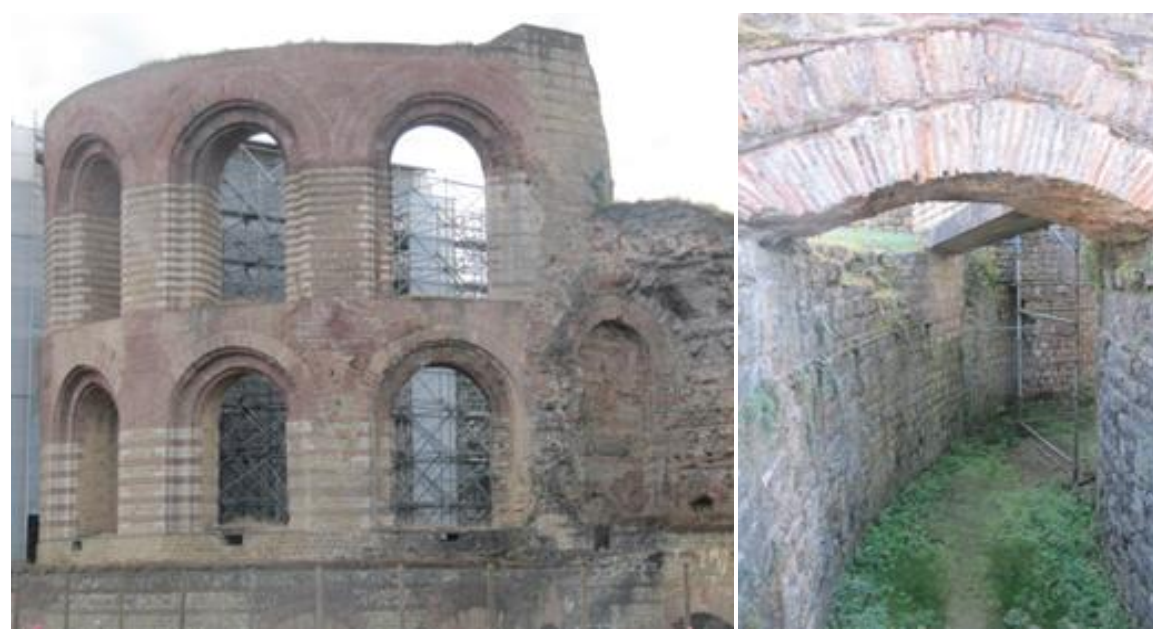

Fig. 6 Overview of the Trier Roman baths

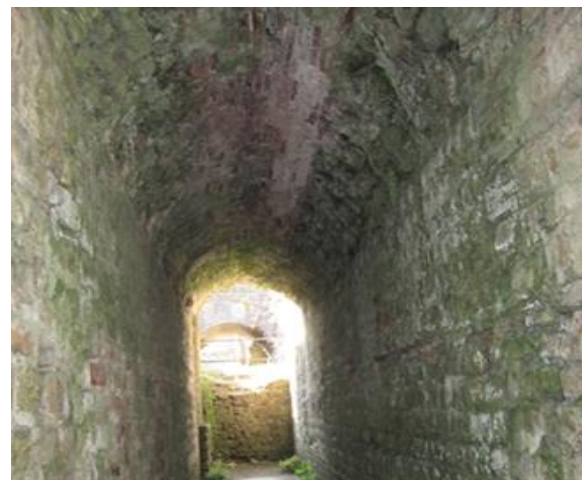

Fig. 7 Unrehabilitation area

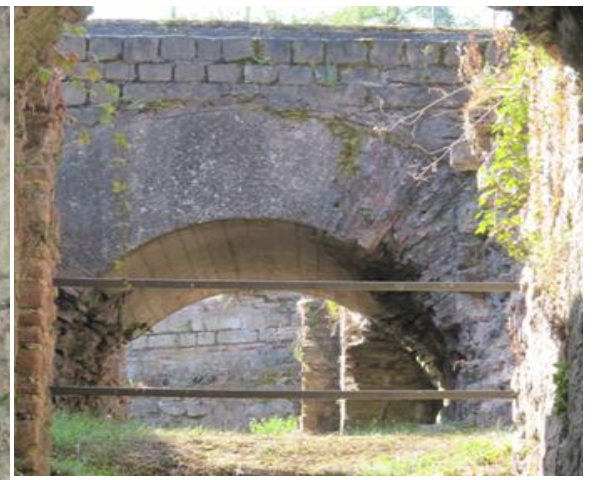

Fig. 8 Rehabilitation area

\section{CONCLUSIONS}

Although, overall, the technical value of archaeological sites is usually considered "research potential", aesthetic values are often overlooked, due to the fact that aesthetics is often interpreted to mean something attractive, as opposed to the broader sense of perception or "sensory feeling, as expressed in the Burra Charter.

However, archaeological excavations that reveal extremely intact and legible remains in the form of aesthetically appealing artifacts, aged and worn fabrics and remaining structures, can allow both professionals and the community to connect with the past through tangible physical evidence, most often the definers in the calculation of the value parameters.

Archaeological sites have the ability to demonstrate how the society functioned at a given time, the level of civilization, the progress of science and technology, what processes have taken place, how the activity unfolded and the extent of a technological practice or other occupation history. They can demonstrate the main characteristics of a place or process that may be rare or common. 


\section{REFERENCES}

[1] Toni Walton- Assessing the archeological values of historic places - Department of Conservation PO-Box 10-420 New Zealand

[2] Arh Radu Cornescu - Exhibition of the development of the modern city of Constanța versus the ancient vestiges

[3] Ana Maria Grămescu - Evaluation of Historical Properties Part I - Ed MATRIX Bucharest 2017 - ISBN 978-606-25-0339-0

[4] Ana Maria Grămescu, A.M.Daniela Barbu "Repair and consolidation of constructions" AGIR Bucharest Publishing House 2008, ISBN 973 - 720 - 042 - X

[5] Ana Maria Grămescu et. all, "Evaluation of specialized properties in constructions", vol. I, EX PONTO Publishing House, ISBN: 973 - 644 - 520 -8 code 624, Constanta 2006

[6] Barbu Daniela, Gramescu Ana Maria "Aspects regarding the valuation of historical properties" Asian Real Estate Society (AsRES) and the American Real Estate and Urban Economics Association (AREUEA) International Conference will take place July 7 - 10, 2014 in Romania

[7] Barbu Daniela, Gramescu Ana Maria - "Aspects on market value estimates of real estates considered as spiritual heritage of communities in the Dobroudja area" - published in the Bulletin of the Polytechnic Institute Iasi Dec 2010 volume LIV (LVIII), fascicola 2

[8] Barbu Daniela, Gramescu Ana Maria, Ionescu Victor - "Methods of statistical analysis used in values reconciliation of real estate properties" - The 15th Asian Real Estate Society (AsRES) International Conference July 9-12, 2010, Kaohsiung city, Taiwan, Department of Urban Planning - Cheng Kung University Taiwan

[9] Gramescu Ana Maria, Barbu Daniela - "Contributions regarding urban development criterion in land and buildings valuation" - the first International Conference on sustainable urbanization (ICSU2010), Faculty of Construction and Land Use, the Hong Kong Polytechnic University July 2010

[10] Grămescu Ana Maria, Gelmambet Sunai, Dragoi Mihaela - "Contributions to the mechanical behavior of natural stone masonry of Muslim places of worship belonging to the Dobroudja area" - IWAN Center for Architectural Heritage, Faculty of Engineering, Islamic University of Gaza-Palestine April 19-20, 2010

[11] Barbu Ana Maria Daniela, Grămescu Ana Maria, Amedeo Mitroi - "Considerations regarding the Valuation of the Specialized Properties", published in the Bulletin of the Polytechnic Institute of Iasi - hydrotechnical section, volume LIV, fasc 3/2008

[12] Ana Maria Grămescu - "The history of the monument in Romania and the concept of rehabilitation" of the 9th International Symposium on Historical Bearing Structures October 22, 2005 - Cluj Napoca

[13] xxx 016 List of historical monuments - County Direction for Culture Constantza

Note:

Ana Maria Gramescu - Ovidius University of Constanta, Institute of Doctoral Studies, Bd. Mamaia nr. 124, 900356-Constanta, Romania (e-mail: am_gramescu@yahoo.com)

Ana Maria Daniela Barbu - Management Expert International SRL, str. G-ral Eremia Grigorescu, 810044. Braila, Romania

Alexandru Ioniță - PhD, Ovidius University of Constanta, Institute of Doctoral Studies, Bd. Mamaia nr. 124, 900356-Constanta, Romania (corresponding author to provide e-mail: alexionita 76 @ yahoo.com) 